\title{
AC 2010-1634: CONFLICT BEHAVIOR AND ITS INFLUENCE ON ENGINEERING DESIGN TEAMS
}

\section{Xaver Neumeyer, Northwestern University}

\section{Ann McKenna, Northwestern University}

Ann F. McKenna is the Director of Education Improvement in the McCormick School of Engineering and Applied Science at Northwestern University. She also holds a joint appointment as a Professor in the School of Education and Social Policy as well as a Professor in the Department of Mechanical Engineering and is the co-Director of the Northwestern Center for Engineering Education Research (NCEER). She received her BS and MS degrees in Mechanical Engineering from Drexel University and Ph.D. in Science and Mathematics Education from the University of California at Berkeley. 


\title{
CONFLICT BEHAVIOR AND ITS INFLUENCE ON ENGINEERING DESIGN TEAMS
}

\begin{abstract}
Our work is investigating the nature and perceptions of team conflict from the student as well as the faculty perspective through the use of team observations, student and faculty surveys, as well as faculty interviews. In particular, we are interested in determining the most common types of conflicts among students as well as the conflict-management strategies they utilize. Questions asked in the surveys and interviews ranged from general evaluation of teamwork to student and faculty perceptions of productive conflict. The main conflicts that were reported in our study included conflicts of commitment, different ideas about the project direction as well as different working styles.

Results from this research will enable us to rethink common models of team conflict and develop direct and indirect intervention strategies that can help students to better integrate emotion and intellect in engineering design and innovation.
\end{abstract}

\section{Introduction}

Although design projects and course structures may vary, there has been a consistent attempt to integrate team experiences into the engineering design curriculum ${ }^{1-5}$. While there has been significant work that describes instructional approaches for integrating and assessing teamwork, very few studies have explored the role that team conflict has on students' team performance in the context of engineering design education ${ }^{3,6}$.

The current work addresses student and faculty perspectives on team conflict as well as conflict-management strategies. Understanding the mechanics and potential beneficial effects of team conflict offers new insights for engineering educators who emphasize teamwork in their courses or design projects.

\section{Past and current models of team interaction and conflict}

The predominant model of group development synthesized by Tuckman describes different stages of group development: forming, storming, norming, performing as well as adjourning ${ }^{7}$. However, the issue of team conflict has not been specifically addressed in this model although Maples et al. emphasized that the highest amount of conflict, concern, confrontation and criticism arises in the storming stage ${ }^{8}$.

To better integrate conflict into the group development process Gemmill and Wynkoop proposed a psychometric model consisting of the following phases and transitions: (1) 'hanging on' which involves intellect only (2) 'working through' which involves emotions only (3) 'letting go', which comes with an agglomeration of intellect and emotions and (4) 'moving beyond' where intellect and emotions are integrated. At any of these points, the group may fail to make the transition, which can consequently lead to regressive solutions such as defensive routines, refusal to deal with emotions or "scapegoating" 9 . 
Taken together, these research findings indicate that team conflict is an important mechanism influencing the integration of emotion and intellect. Therefore, it needs more attention in the context of teaching engineering design and innovation. Therefore, this research will show common conflict patterns and conflict-management strategies, including productive forms of conflict that are present in student engineering design and innovation.

\section{Methodology}

To explore the nature of team conflict and its impact on team performance our current work is investigating the following research questions:

- What is the nature of team conflict in student design teams?

- How do students and their instructors manage these team conflicts?

- What do students and instructors learn from team conflict?

In order to capture these questions, the study was split into three parts: (1) faculty interviews (2) team observations and (3) student and faculty surveys. However, due to time and space restrictions, we will only focus on the results from the interviews and surveys.

\section{Study participants}

The participants of this study - both students and faculty - were recruited from three classes: (1) Engineering Design and Communication (EDC), (2) Interdisciplinary Design Projects (IDP), and (3) Medical Innovation (MI). EDC is a first year undergraduate design class spanning two quarters. It is a requirement for all incoming engineering students (approximately 400). EDC consists of several sections with each having about 16 students and two instructors (engineering and writing). In the first quarter, all four teams in a section work on the same project. The projects focus on universal design and can range from designing assistive technologies for stroke survivors to newly designed field-hockey sticks for the disabled.

The IDP course is a two quarter sequence and is intended for undergraduate students at the junior or senior level. The format is similar to EDC and focuses on team-based design. Typically, enrollment is around 25 students per quarter. Furthermore, two instructors (engineering and writing) and a variety of advisors help oversee the student teams.

MI is a two-quarter sequence targeted at graduate students from the engineering, medical, law and business school programs. Medical Innovation is based on experiential learning and team-based processes. Student teams consist of about 8-9 members and two instructors. Teams go through the phases of ideation, prototyping, legal protection, market sizing and business plan development. In contrast to EDC and IDP where a client 
has pre-defined project, the MI students have to find their own project through observation and shadowing. Typical enrollment is about 65 students.

The student surveys were sent to 147 EDC students, 65 MI students, and 25 IDP students, totaling 237 students in all three courses. Response rates were as follows: (a) $45 \%$ ( $=$ 67) for EDC, (b) 36\% (N=10) for IDP, and (c) 38\% (N=25) for MI. We also interviewed 20 faculty members from all three classes with each interview lasting from 30 minutes to about two hours. Furthermore, did we recruit 30 more faculty members for surveys. The response rate for the faculty surveys was $45 \%(\mathrm{~N}=14)$.

\section{Faculty interviews}

Interviewed faculty consisted of former instructors that were chosen based on their experience with team-based design or innovation classes as current or former instructors. The interviews were constructed to conduct exploratory research on faculty observations of conflict as well as on conflict-management strategies. Faculty, were first asked general questions about the course and teamwork, followed by more conflict-oriented questions. The questions we developed were formulated so as to explore factors for (a) sources of conflict, (b) conflict-management strategies of students, (c) own experiences with conflict, (d) the productive side of conflict, and (e) others (see Table 1). We followed a semi-structured interview protocol such that we identified several questions to ask a priori. However, the interview was conducted in a conversational in order to give the interviewer or interviewee the possibility to ask follow-up or clarifying questions as necessary.

Although we were aware of existing team conflict and conflict management categories ${ }^{10}$

${ }^{11}$, we developed our own classifications that were based on faculty responses.

\begin{tabular}{|l|l|}
\hline \multicolumn{1}{|c|}{ Interview question } & \multicolumn{1}{|c|}{ Purpose } \\
\hline $\begin{array}{l}\text { 1. Please name two positive and negative } \\
\text { aspects of EDC/MI/IDP? }\end{array}$ & $\begin{array}{l}\text { Gives us a picture of the instructor's } \\
\text { perspective of team-based classes }\end{array}$ \\
\hline $\begin{array}{l}\text { 2. What are the most common sources of } \\
\text { team conflict that you have observed among } \\
\text { student design teams over the years? }\end{array}$ & $\begin{array}{l}\text { Establishes a description of team conflict } \\
\text { from the instructor perspective. }\end{array}$ \\
\hline $\begin{array}{l}\text { 3. Please describe the strategies that students } \\
\text { use to manage conflicts in their teams }\end{array}$ & $\begin{array}{l}\text { Explores the instructor's observations on } \\
\text { conflict management strategies. }\end{array}$ \\
\hline $\begin{array}{l}\text { 4. What types of conflict as well as conflict } \\
\text { management strategies have you encountered } \\
\text { in your professional career? }\end{array}$ & $\begin{array}{l}\text { Provides more personal information } \\
\text { about conflict. }\end{array}$ \\
\hline $\begin{array}{l}\text { 5. How would you define productive } \\
\text { conflict? }\end{array}$ & $\begin{array}{l}\text { Aims at faculty perception of productive } \\
\text { conflict. }\end{array}$ \\
\hline
\end{tabular}

Table 1.Faculty interview questions

For example, when faculty responded to question 2 that "some students just didn't pull their weight (Instructor A in EDC)" we categorized that as different levels of commitment. Other conflict categories were different skill-sets, different ideas about the 
project direction, different personalities, and different working styles. These conflict categories would then be implemented into a forced-choice question that was implemented into the student and faculty surveys. Among the categories for question 3 were: division of labor, absorbing extra work as well as assigning low-level tasks for low-achievers. Categories for question 4 and 5 are still under investigation. However, we included statements that we considered relevant for the discussion.

\section{Faculty surveys}

Faculty that could not be covered through interviews was surveyed using questions similar to Table 2. Question 2 was the only exception because it was converted into a forced-choice question.

\section{Student surveys}

The items in the student surveys were developed based on the research questions, the focus of the courses, and faculty responses in the preliminary interviews. The survey included both forced-choice and open-ended questions. The open-ended questions aimed to capture students' perspectives on teamwork in general, experiences of team conflict, in addition to questions about how students managed conflict, and if any of the conflicts they experienced were productive (see Table 2). Responses to question 2 were rated on a 3-point scale and subdivided into 1- rarely an issue, 2- sometimes an issue and 3- often an issue. The authors chose three-point scales because they are less cumbersome for respondents, thereby increasing response rates.

\begin{tabular}{|l|l|}
\hline \multicolumn{1}{|c|}{ Survey question } & \multicolumn{1}{|c|}{ Purpose of the question } \\
\hline $\begin{array}{l}\text { 1. Please describe your two most positive } \\
\text { and negative experiences with teamwork in } \\
\text { EDC/MI/IDP? }\end{array}$ & $\begin{array}{l}\text { Establishes a base line of how teamwork is } \\
\text { perceived among students. }\end{array}$ \\
\hline $\begin{array}{l}\text { 2. What were the main sources of conflict } \\
\text { you experienced in your team? }\end{array}$ & $\begin{array}{l}\text { Indentifies the sources of conflict perceived } \\
\text { by the students as well as their frequency. }\end{array}$ \\
\hline $\begin{array}{l}\text { 3. Pick one or two conflict(s) that you } \\
\text { experienced from the list above and explain } \\
\text { how they affected your team }\end{array}$ & $\begin{array}{l}\text { Establishes a more detailed description of } \\
\text { students' perception of conflict as well as } \\
\text { its impact on their team performance. }\end{array}$ \\
\hline $\begin{array}{l}\text { 4. How did the team manage those } \\
\text { conflicts? }\end{array}$ & $\begin{array}{l}\text { Investigates the strategies that students } \\
\text { used to deal with team conflicts. }\end{array}$ \\
\hline $\begin{array}{l}\text { 5. Did you think that any of the conflicts } \\
\text { you experienced were productive and help } \\
\text { your team perform better? Please explain }\end{array}$ & $\begin{array}{l}\text { Evaluates students' understanding of } \\
\text { productive conflict. }\end{array}$ \\
\hline
\end{tabular}

Table 2.Student survey questions

Question 3 is an addition to the forced-choice of question 2, thus was not categorized. Categories for question 4 were coded similar to question 4 of the faculty interviews. For example, when students stated that "We gave him assignments we thought he could handle, such as the less technical writing, and put him in charge of "advertising" such as the presentation at the poster fair. We also just absorbed the extra work to an extent. 
(Student C)" we would code that as assigning non-critical tasks to the low-achiever(s). Responses for question 5 will be included in form of selected statements.

\section{Findings}

Extracting the positive and negative aspects of teamwork was the first part of the interviews and surveys, providing us with trends as to which circumstances of teamwork lead to conflict among students (see Tab. 3).

\begin{tabular}{|c|c|c|}
\hline \multicolumn{3}{|c|}{ Positive } \\
\hline Shared goals & Even division of labor & Variety of ideas \\
\hline Trust & Establishing of relationships & $\begin{array}{l}\text { Learn how to manage } \\
\text { team members }\end{array}$ \\
\hline \multicolumn{3}{|c|}{ Motivation } \\
\hline \multicolumn{3}{|c|}{ Negative } \\
\hline Uneven work-loads & Ill-conceived team meetings & $\begin{array}{l}\text { Lack of dedication to a } \\
\text { final goal }\end{array}$ \\
\hline $\begin{array}{l}\text { Lack of self-motivation } \\
\text { Lack of commitment }\end{array}$ & $\begin{array}{c}\text { Lack of trust } \\
\text { Lack of perseverance }\end{array}$ & Burden of responsibility \\
\hline Uneven contribution levels & Scheduling conflicts & Lack of commitment \\
\hline
\end{tabular}

Table 3.Positive and negative factors associated with teamwork

The majority of students balanced positive and negative associations with teamwork. However, some students expressed their frustration about teamwork ("Because half of the team did little or no significant work, the entire project was essentially left to me and one other person which made it extremely stressful and difficult to get the project done") (Student D in EDC). Others conveyed more enthusiasm about their team interactions ("Everyone on the team did an absolutely fantastic job, and really pulled their weight! It was a pleasure working with everyone, and I learned so much from everyone") (Student $\mathrm{B}$ in $\mathrm{MI})$.

In general, some faculty members expressed their skepticism about the students' understanding of teamwork ("Some students do not understand the real value of a team, they think it is something similar to a study group") (Instructor in MI). Others explained that high-achievers immediately establish a performance hierarchy based on each team members' skill and ambition that can often lead to team conflict.

Figure 2 shows the most frequently experienced team conflicts among student teams, corresponding to a frequency level of 3 (- often an issue), for all three courses. The data suggests that students of all levels reported those of commitment as the most frequently experienced team conflicts. Furthermore, MI and IDP students reported a high portion of project direction conflicts. This might be rooted in the IDP and MI students' higher level of expertise, thus creating more conflicts that are related to project direction and skillsets. 
Personality conflicts on the other hand seem to have been more of an issue with EDC students than with students of the other two classes.

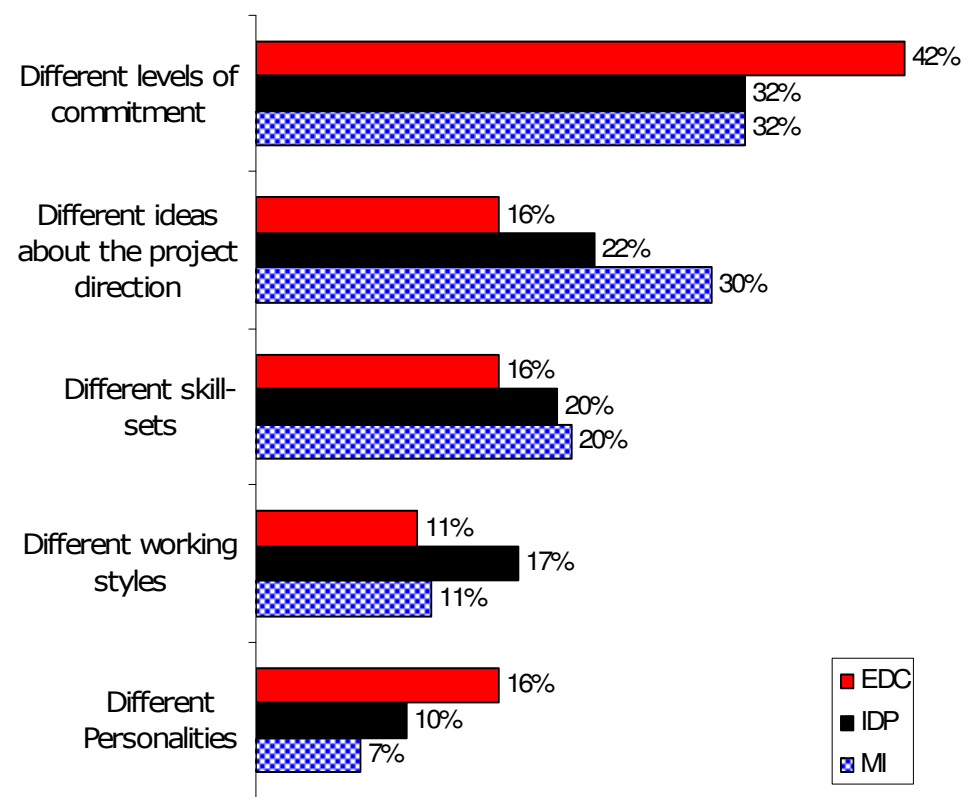

Figure 1.Most frequently perceived team conflicts among students from all three courses

It was surprising to see that IDP students reported the highest share of working style conflicts. Nevertheless, due to the low response rate $(\mathrm{N}=10)$ of the IDP sample we could not draw any convincing conclusions. Furthermore, is the distribution of different conflict categories very consistent with faculty responses in the surveys and interviews.

\section{Conflict-management strategies}

The second objective of this study was to evaluate the conflict-management strategies of student design teams. Therefore, both faculty and student surveys were analyzed in addition to faculty interviews. Figure 2 demonstrates that students utilize a variety of conflict-management strategies ranging from division of labor to voting. The data also suggests that EDC students reported a significant percentage, about $26 \%$, of regressive strategies such as scapegoating or assigning non-critical tasks to the low-achiever. In contrast to EDC students, IDP and MI students reported a higher percentage of progressive strategies such as discussion (21 and 27\%). 


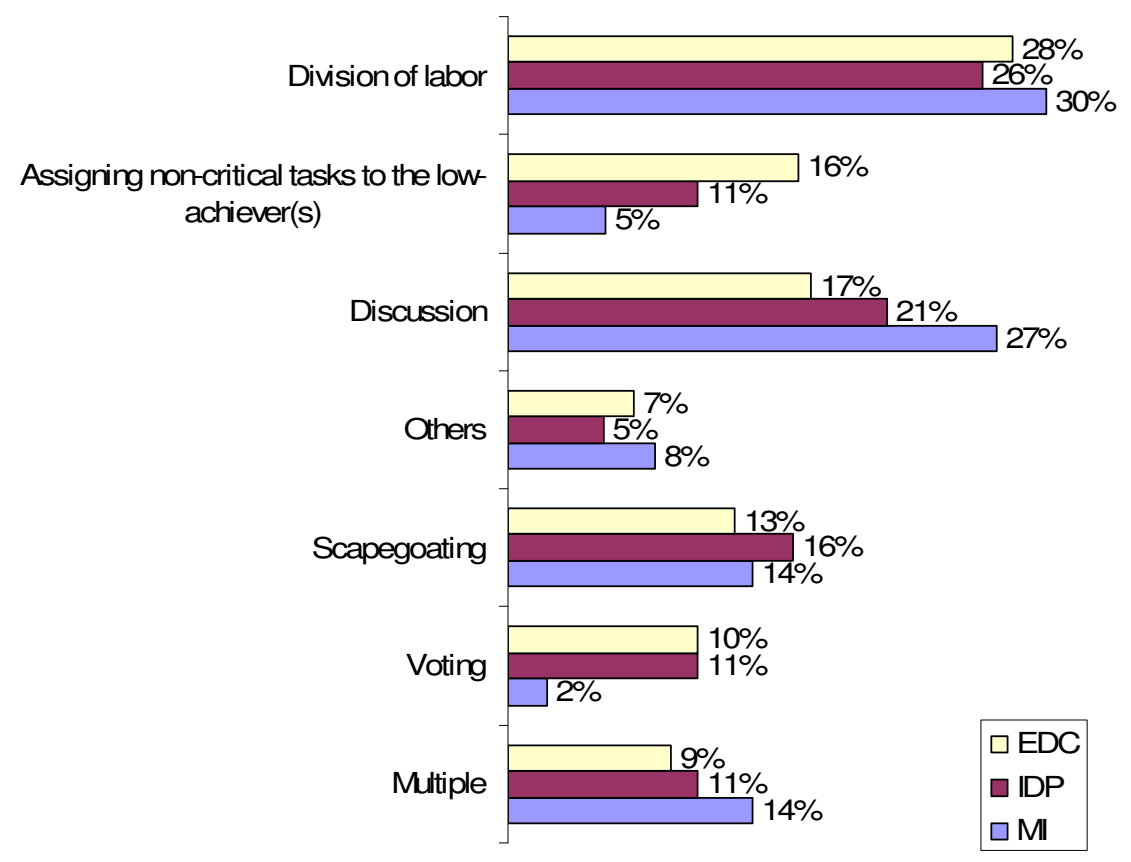

Figure 2.Conflict-management strategies reported by students form all three courses

In summary, we extracted a variety of regressive and progressive conflict-management strategies from faculty from the survey and interview data. The definition of "regressive" and "progressive" was based on past research" as well as faculty comments.

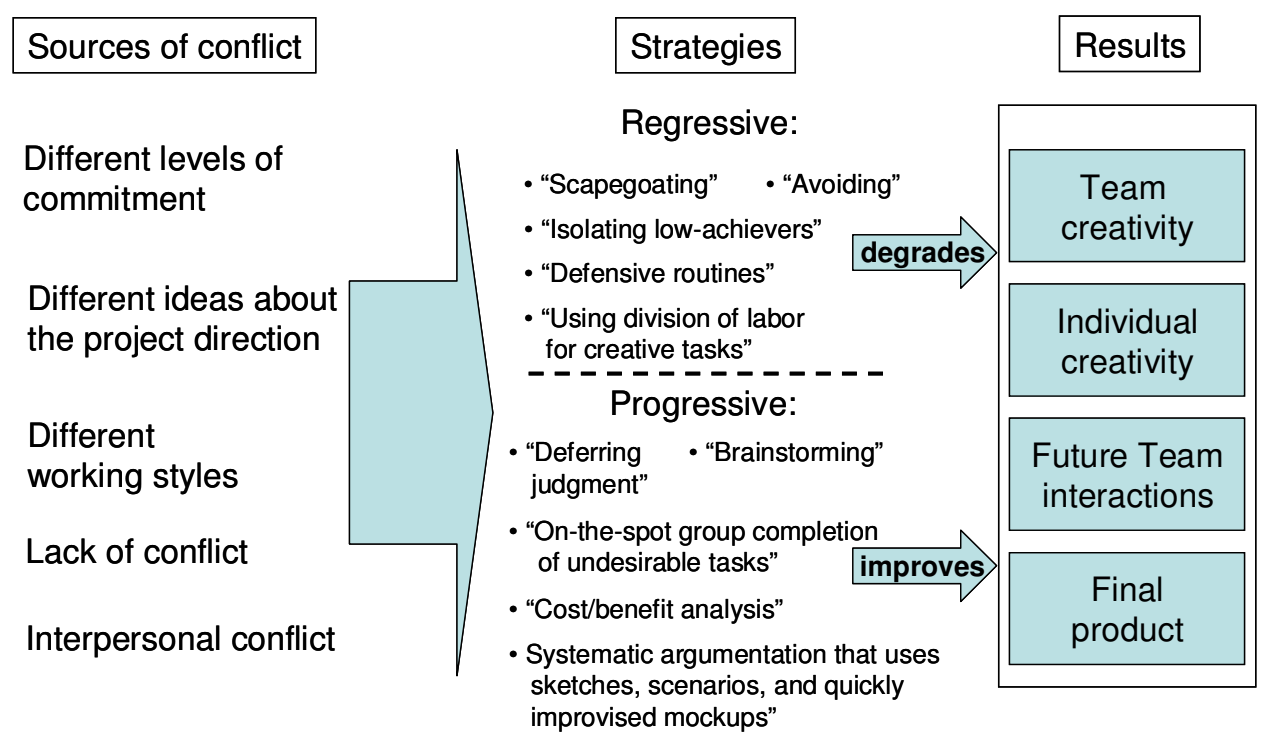

Figure 3.Summary of conflict sources and conflict management strategies 


\section{Productive conflict}

The final part of the study targeted both instructors' and students' views on productive conflicts. $65 \%(\mathrm{~N}=154)$ of all students reported that their experience with team conflicts was productive while $35 \%(\mathrm{~N}=83)$ could not extract any value from them. Figure 3 shows the variety of student statements about the results of their team conflicts, ranging from denying the value of team conflict to openly embracing adversity and argumentation. It should also be noted, that students are often faced with two options: (1) risking "group frustration", thus slowing the team down or (2) spurring a productive discussion that could lead to a design improvement.

\begin{tabular}{|c|l}
\hline Not really no, most of them were just an inconvenience and slowed our team down \\
(Student A)
\end{tabular}

Figure 4.Student statements about productive team conflict

As for the faculty, some stated that "conflict is productive when it leads to increased understanding of different options/viewpoints, and a stronger rationale for decisions made" (Instructor C in EDC). Others define productive conflict as "conflict that leads to some type of action (including decision as an action) that is more productive than the action that would have been taken had the conflict not existed" (Instructor D in MI).

It should be noted that a large number of faculty relate the definition of productive conflict to their conflict-management style. For example, faculty members that tend to be confrontational in conflicts, emphasize argumentation as a main criterion of productive conflict, whereas faculty or instructors that tend to avoid conflicts see compromise as the means to productively deal with team conflicts. 


\section{Discussion and Future Work}

The goal of this paper was to extract the main categories of team conflicts and conflictmanagement strategies that students experience and their instructors observe. The main sources of conflicts we found were: conflicts of commitment, project direction, and different working styles. Although the data suggests that students in MI and IDP reported fewer commitment conflicts and more conflicts about ideas and working styles, it is still unclear if this is mainly attributed to structural characteristics of the class or their higher seniority. Furthermore, do the results indicate that students of all seniority levels display a variety of complex conflict-management strategies ranging from assigning non-critical tasks to low-achievers to actively engaging in confrontational discussions about their design.

The question of how students deal with "perceived" low-achievers in their teams is very interesting. Instructors would often consider it a pedagogical dilemma:

"Trying to bring the whole group [referring to the student team] back to the same level, would cause the deliverables and the design to get stuck. We certainly don't encourage that [assigning non-critical tasks to the perceived low-achiever(s)], but sometimes I just know that bringing everyone back to the same level will not work, although its pedagogically not desirable" (Instructor B from EDC).

This issue goes back to the question of how instructors can enhance performance as well as learning in teams ${ }^{12}$. Therefore, we will dedicate more attention to this phenomenon in the future.

While we were analyzing student survey responses we discovered that a large number of EDC students mentioned the pronounced effect that design review, prototyping as well as brainstorming had on their team conflicts. For example, some students mentioned how the design review helped readjusting some of their team's agendas:

"At first it seemed to the team members with less building experience that the other team members were being closed-minded about their ideas. After the design review we were more capable of dealing with these conflicts by addressing them openly and discussing how the less-experienced team members felt. It was soon clear that the other team members were not just throwing out ideas, but identifying their flaws and evaluating their feasibility."(Student G in IDP)

Therefore, we need to incorporate questions about the influence of design process steps such as brainstorming, design reviews and prototyping into our future surveys.

Furthermore, are we investigating the use of existing techniques such as Latent semantic analysis (LSA) or verbal content analysis ${ }^{13,14}$ to analyze the team observations we collected and are currently reviewing.

There are several future research directions that could be of interest to this study. A number of researchers already pointed out, that different personalities can have a 
pronounced impact on team performance ${ }^{15,16}$. Therefore, including psychometric measurements such as the Myers-Briggs Temperament Indicator (MBTI) into our investigation could help us find any correlations between conflict patterns and personalities in student design and innovation teams. Several researchers such as Robbins, Dyer and Schulz-Hardt have already pointed out that team conflict can have pronounced effects on team outcomes ${ }^{17-19}$.

Having instructors comment on issues such as perceived conflicts and conflictmanagement strategies provided an important perspective, and helped us identifying team conflicts that were rendered either regressive or progressive by various strategies (see Figure 4). Although, we did not include faculty statements about their personal experience with team conflict, most of them reported that increasing self-awareness and life experience helped manage conflicts in their professional career.

Integrating all the above-mentioned perspectives, could provide us with a deeper understanding of how we might redesign exercises in order to help students transition from individual ownership to collective ownership of ideas and skills.

Bibliography

1. McKenna, A.F., et al., IDEA: Formalizing the foundation for an engineering design education. International Journal of Engineering Education, 2006. 22(3): p. 671-678.

2. Colgate, J.E., A. McKenna, and B. Ankenman, IDEA: Implementing design throughout the curriculum at Northwestern. International Journal of Engineering Education, 2004. 20(3): p. $405-$ 411.

3. Dym, C.L., et al., Engineering design thinking, teaching, and learning. Journal of Engineering Education, 2005. 94(1): p. 103-120.

4. Kolodner, J.L., et al., Problem-based learning meets case-based reasoning in the middle-school science classroom: Putting Learning by Design (TM) into practice. Journal of the Learning Sciences, 2003. 12(4): p. 495-547.

5. Davis, D., S. Beyerlein, K. Harrison, P. Thompson, M. Trevisan, and B. Mount. Assessment Framework for Capstone Design Courses in Proceedings of American Society for Engineering Education 2006.

6. Song, M., B. Dyer, and R.J. Thieme, Conflict management and innovation performance: An integrated contingency perspective. Journal of the Academy of Marketing Science, 2006. 34(3): p. 341-356.

7. Tuckman, B.W., Developmental Sequence in Small-Groups. Psychological Bulletin, 1965. 63(6): p. 384-399.

8. $\quad$ Maples, M.F., Group development: Extending Tuckman's theory. Journal for Specialists in Group Work, 1988. 13(1): p. 17-23.

9. Gemmill, G. and C. Wynkoop, The Psychodynamics of Small-Group Transformation. Small Group Research, 1991. 22(1): p. 4-23.

10. Jehn, K.A., Qualitative analysis of conflict types and dimensions in organizational groups. Administrative Science Quarterly, 1997. 42(3): p. 530-557.

11. Rahim, A., Rahim organization conflict inventory-II. 1990, Palo Alto, California: Consulting Psychologist's Press.

12. Davis, D., S. Beyerlein, K. Harrison, P. Thompson, M. Trevisan, and B. Mount. Conceptual Model for Capstone Engineering Design Peformance and Assessment. in Proceedings of American Society for Engineering Education Annual Conference. 2006. Chicago, IL. 
13. Atman, C.J., J.R. Chimka, and K.M. Bursic, Results from a verbal protocol study of the design process. Frontiers in Education 1997 - 27th Annual Conference, Proceedings, Bols I - Iii, 1997: p. 1283-1295.

14. Dong, A., A.W. Hill, and A.M. Agogino, A document analysis method for characterizing design team performance. Journal of Mechanical Design, 2004. 126(3): p. 378-385.

15. Barrick, M.R., G.L. Stewart, and M. Piotrowski, Personality and job performance: Test of the mediating effects of motivation among sales representatives. Journal of Applied Psychology, 2002. 87(1): p. 43-51.

16. Reilly, R.R., G.S. Lynn, and Z.H. Aronson, The role of personality in new product development team performance. Journal of Engineering and Technology Management, 2002. 19(1): p. 39-58.

17. Dyer, B. and X.M. Song, Innovation strategy and sanctioned conflict: A new edge in innovation? Journal of Product Innovation Management, 1998. 15(6): p. 505-519.

18. Robbins, S.P., Managing Organizational Conflict: A Non-traditional Approach. 1974, Englewood Cliffs, NJ: Prentice-Hall.

19. Schulz-Hardt, S., M. Jochims, and D. Frey, Productive conflict in group decision making: genuine and contrived dissent as strategies to counteract biased information seeking. Organizational Behavior and Human Decision Processes, 2002. 88(2): p. 563-586. 